\title{
Predator Effects in Predator-Free Space: the Remote Effects of Predators on Prey
}

\author{
John L. Orrock ${ }^{*}, 1,2 \dagger$, Lawrence M. Dill ${ }^{3}$, Andrew $\operatorname{Sih}^{4}$, Jonathan H. Grabowski, \\ Scott D. Peacor ${ }^{6}$, Barbara L. Peckarsky ${ }^{6}$, Evan L. Preisser ${ }^{7}$, James R. Vonesh $^{8}$ and \\ Earl E. Werner ${ }^{9}$
}

\author{
${ }^{I}$ Department of Zoology, University of Wisconsin, Madison, WI 53706, USA \\ ${ }^{2}$ Department of Biology, Washington University, Saint Louis, MO 63130, USA \\ ${ }^{3}$ Behavioural Ecology Research Group, Department of Biological Sciences, Simon Fraser University, Burnaby, BC, \\ Canada V5A 1 S6 \\ ${ }^{4}$ Department of Environmental Science and Policy, University of California, Davis, CA 95616, USA \\ ${ }^{5}$ Gulf of Maine Research Institute, 350 Commercial Street, Portland, ME 04101, USA \\ ${ }^{6}$ Department of Fisheries and Wildlife, Michigan State University, Ann Arbor, MI 48105, USA \\ ${ }^{7}$ Department of Biological Sciences, University of Rhode Island, Kingston, RI 02881, USA \\ ${ }^{8}$ Department of Biology, Virginia Commonwealth University, Richmond, VA 23284, USA \\ ${ }^{9}$ Department of Ecology and Evolutionary Biology, University of Michigan, Ann Arbor, MI 48109, USA
}

\begin{abstract}
Predators can have remote effects on prey populations that are connected by migration (i.e. prey metapopulations) because predator-mediated changes in prey behavior and abundance effectively transmit the impact of predators into predator-free prey populations. Behavioral changes in prey that might give rise to remote effects are altered rates of migration or activity in the presence of predation risk (called non-consumptive effects, fear- or $\mu$-driven effects, and risk effects). Changes in prey abundance that may result in remote effects arise from changes in prey density due to direct predation (i.e. consumptive effects, also called N-driven effects and predation effects). Remote effects provide a different perspective on both predator-prey interactions and spatial subsidies, illustrating how the interplay among space, time, behavior, and consumption generates emergent spatial dynamics in places where we might not expect them. We describe how strong remote effects of predators may essentially generate "remote control" over the dynamics of local populations, alter the persistence of metapopulations, shift the importance of particular paradigms of metacommunity structure, alter spatial subsidies, and affect evolutionary dynamics. We suggest how experiments might document remote effects and predict that remote effects will be an important component of prey dynamics under several common scenarios: when predators induce large changes in prey dispersal behavior, when predators dramatically reduce the number of prey available to disperse, when prey movement dynamics occur over greater distances or shorter timescales than predator movement, and when prey abundance is not already limited by competitors or conspecifics.
\end{abstract}

Keywords: Anti-predator behavior, dispersal, non-consumptive effects, predator-prey dynamics, remote control, spatial ecology, subsidies.

\section{INTRODUCTION}

Predators can affect prey dynamics by consuming prey or by non-consumptive effects, including influences on the morphological, developmental or behavioral traits of prey (e.g., habitat selection, metamorphosis, vigilance, migration; Lima and Dill 1990, Lima 1998, Brown et al. 1999, Peckarsky et al. 2001, Werner and Peacor 2003, Brown and

*Address correspondence to this author at the Department of Zoology, University of Wisconsin, Madison, WI, 53706, USA; Tel: 314-935-5818; Fax: 314-935-4432; E-mail: jorrock@wisc.edu

${ }^{\dagger}$ Authors listed in alphabetical order after first three authors.

Special Issue Editor: John W. Laundre
Kotler 2004). Often, predators affect prey by a combination of consumptive and non-consumptive effects (Brown et al. 1999, Peacor and Werner 2001, Werner and Peacor 2003, Preisser et al. 2005, Creel and Christianson 2008). In turn, the effects of predators on prey can be transmitted to other organisms and resources, potentially producing an array of indirect effects (e.g. density- or trait-mediated indirect interactions; see Abrams 2007 for a discussion of concepts and terminology). Despite our knowledge of predatormediated changes in prey dynamics and the common finding that predators and predator cues can change prey movement behavior and migration (McPeek 1989, Lima and Dill 1990, Wooster and Sih 1995, Cronin et al. 2004, Resetarits 2005, Resetarits et al. 2005), most studies focus on the effect of 
predators on prey in patches where the two coincide. This focus persists despite evidence that migration of prey may be an important component of prey population dynamics (e.g., Cooper et al. 1990, Sih and Wooster 1994), that the effect of predators can be transmitted across ecosystems via prey (Vonesh and Osenberg 2003, Knight et al. 2005, Resetarits and Binckley 2009), and that ecological interactions and ecosystem services are mediated by organisms that cross patch boundaries (Polis et al. 1997, Baxter et al. 2005, Kremen et al. 2007, Marczak et al. 2007, McCoy et al. 2009).

Our perspective is that the effect of predators is not limited to populations where prey and predators coincide. Rather, when prey populations are linked by movement (i.e., a metapopulation), many important effects of predators may be manifest in areas where predators are not always found, i.e., predators may have remote effects via their effect on prey migration. Changes in prey migration may arise because predators alter prey movement behavior; such changes have been called fear- or $\mu$-driven effects (Brown et al. 1999), non-consumptive effects (e.g., Preisser et al. 2007, Peckarsky et al. 2008), or risk effects of predators (Creel and Christianson 2008). Changes in prey migration may also arise because predation changes the number of prey available to move, which may be described as $\mathrm{N}$-driven effects (Brown et al. 1999), consumptive effects (e.g., Preisser et al. 2007, Peckarsky et al. 2008), or predation effects of predators (Creel and Christianson 2008). For consistency, we use non-consumptive and consumptive effects to describe the two ways that remote effects may be generated.

Remote effects may be a pervasive, yet understudied, component of predator-prey dynamics; when substantial enough to dictate the dynamics of prey populations, these effects may essentially yield "remote control" by predators of both prey and taxa that interact with prey (e.g. competitors, mutualists), even when those populations are apparently predator-free. The concept of remote effects illustrates how spatial dynamics of predator-prey interactions may be largely underwritten by the predator-mediated flux of prey. Here we provide an overview of the implications of remote effects, suggest systems where they are likely to be important, and provide guidelines for experimentally assessing their influence. Our message is that a complete understanding of the dynamics of populations and communities may require consideration of the impacts of predators elsewhere.

\section{WHAT ARE REMOTE EFFECTS?}

We envision a prey metapopulation where local populations of prey inhabit portions of habitat (patches) that are separated by an uninhabitable matrix; although boundaries and patches may not be completely discrete entities in ecological communities, this framework has been useful for capturing a wide array of ecological dynamics within the context of metapopulations and metacommunities (e.g., Hanski and Gilpin 1997, Leibold et al. 2004). Within each patch, the dynamics of prey (i.e. local prey populations) are governed by patch characteristics and prey migration (i.e., a structured metapopulation; see Gyllenberg et al. 1997). We assume that predators are not capable of simultaneously

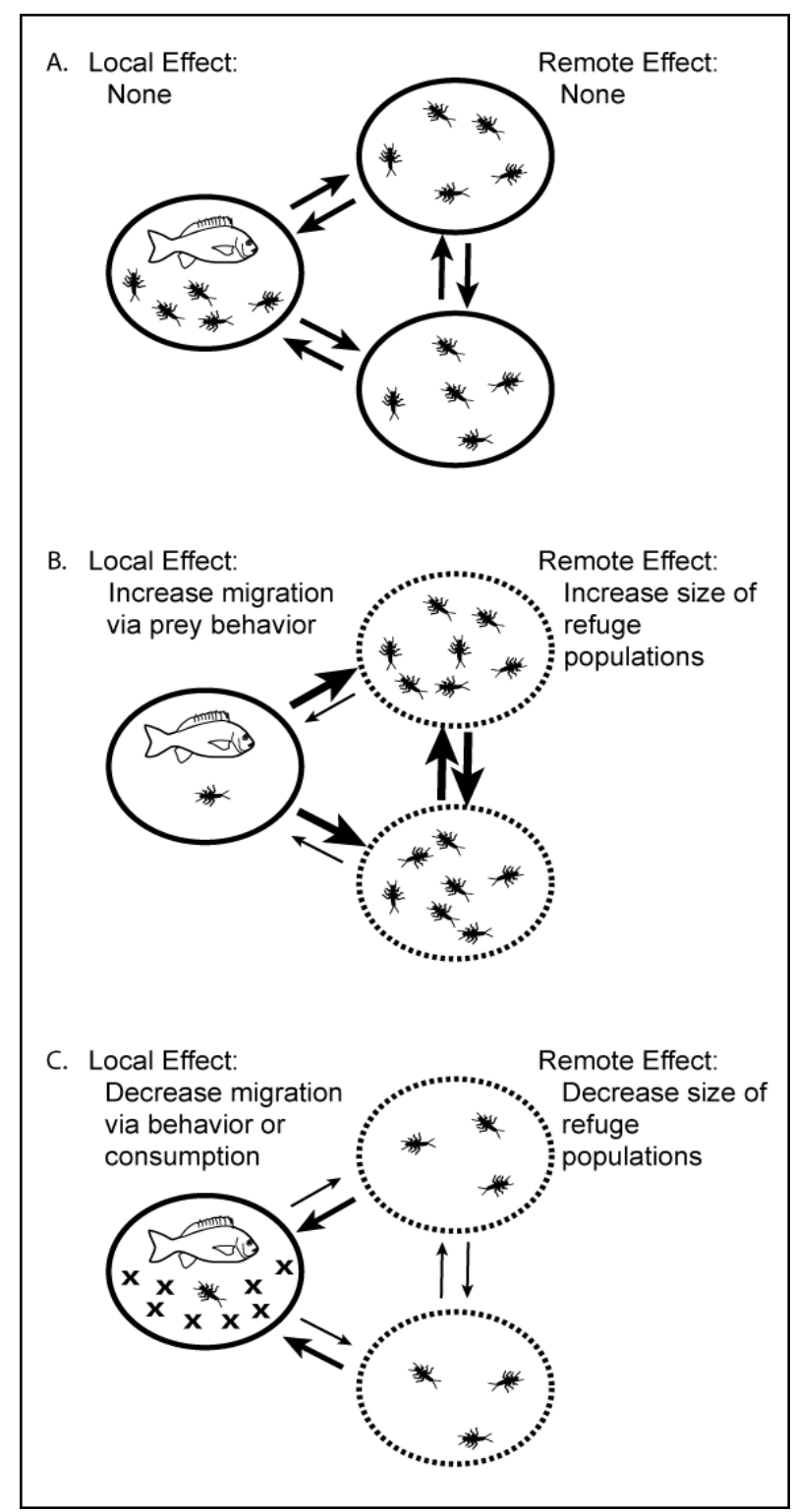

Fig. (1). A conceptual diagram of remote effects when prey have an absolute refuge from predation. In this example, the predator (fish) can access prey (aquatic invertebrates) in one patch (the circled area on the left), but fish cannot access prey in the two patches depicted on the right. Arrows indicate the movement of prey among local prey populations, with arrow size representing the relative rate of movement. Remote effects arise when predators change the flux of prey to remote prey populations by changing prey behavior or abundance in the local patch where predators and prey coincide. Refuge patches that experience remote effects are circled with dotted lines, with changes in the shape and size of arrows depicting net changes in the flux of prey among populations. (A) Without local effects, remote effects cannot be generated. (B) Remote effects arise in predator-free patches when local effects lead to changes in prey migration, e.g., if predators increase the migration rates of prey (a non-consumptive remote effect). (C) Remote effects can also reduce the flux of prey to remote patches via consuming prey or reducing prey migration. Note that remote effects may also alter prey flow among remote populations, as indicated by the change in the size of the arrow linking the two remote prey populations. 


\section{A. System considering only Local Effects}

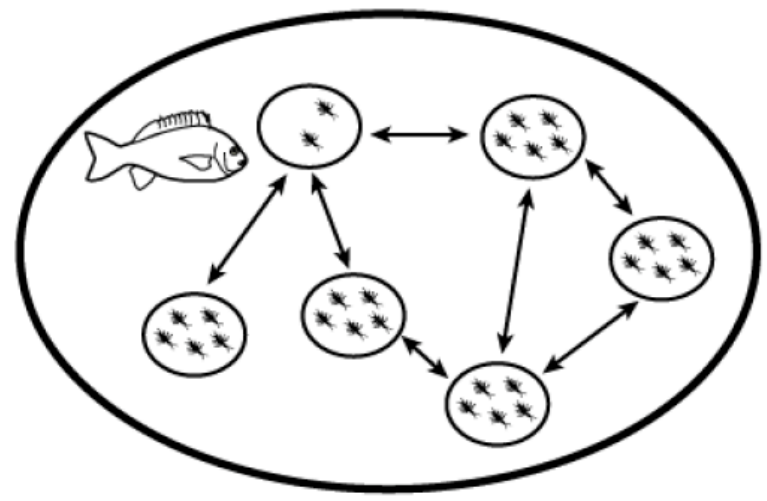

B. Local Effect: Increase migration
via prey behavior

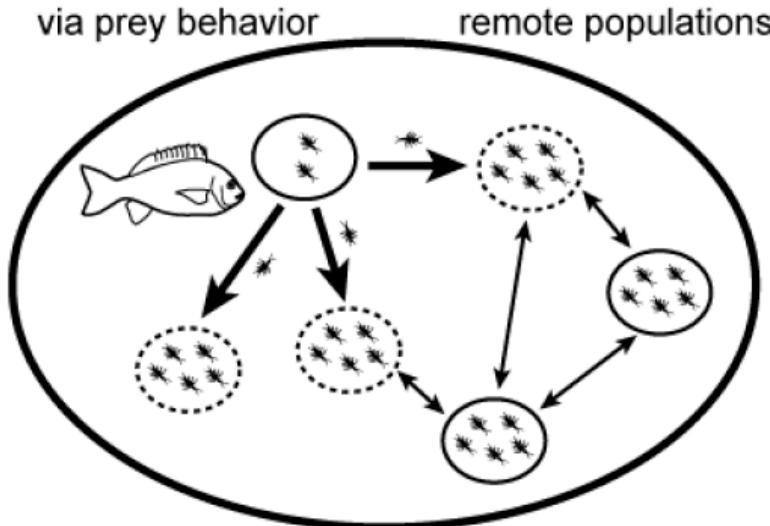

Remote Effect:

Decrease size of remote populations

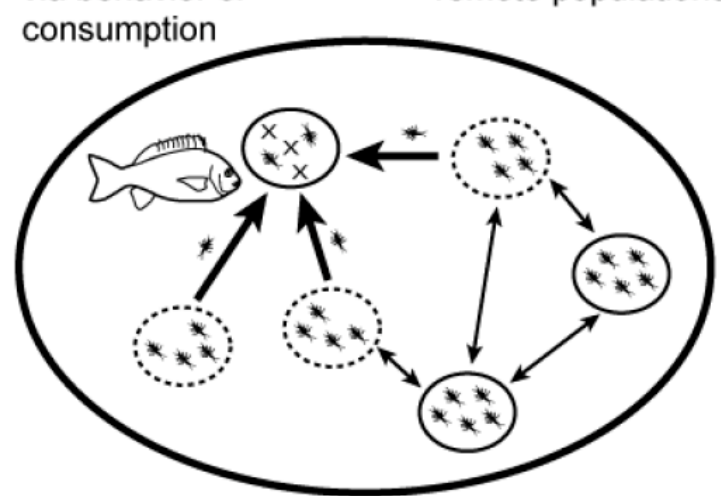

Fig. (2). A conceptual diagram of remote effects when prey have a transient refuge because predators cannot forage among all prey populations at once. In this diagram, fish predators have access to separate local populations of arthropod prey, but cannot simultaneously visit all prey populations. Arrows among local prey populations indicate prey movement. When only local effects are examined (A), the effects of predators are considered to be localized to the prey population the predator is directly affecting, without consideration of how local effects might influence the net flux of prey among local populations. As such, the arrows representing prey movement are not different among local populations when only local effects are considered. The remote effects perspective highlights how, in addition to local effects, predators can have impacts on remote patches of prey by changing rates of prey flux among patches. Predators may increase prey flux to remote patches when prey emigrates in response to predators $(\mathbf{B})$. Predators may decrease the flux of prey to remote patches by consuming prey or by reducing the likelihood that prey will initiate emigration behavior $(\mathbf{C})$. Patches that experience remote effects are circled by dotted lines, with changes in the shape and size of arrows depicting changes in the flux of prey among populations. Regardless of which patch the predator visits during a given time step, a non-zero fraction of the remaining patches experiences the effects of predators via remote effects (in this example, 3 of 6 patches experience remote effects). Although remote effects are limited to three patches to simplify the figure, remote effects may affect all 6 patches by changing flows among remote patches, analogous to the change in prey flux among remote populations in Fig. (1).

exploiting all individual prey populations, i.e., there is a spatial refuge from predation (Fig. 1), or predators are incapable of visiting all prey populations simultaneously, creating a spatiotemporal, or transient (sensu Sih et al. 1985) refuge (Fig. 2). We distinguish between remote effects and other examples of changes in prey foraging behavior due to predation risk (for examples, see Lima 1998, Werner and Peacor 2003, Schmitz et al. 2004, Creel and Christianson 2008), e.g. changes in foraging behavior within a patch, and shifts in prey foraging among different microhabitats within a patch. Such responses of prey are undoubtedly important; however, to highlight the spatial dynamics that characterize remote effects, we focus on situations where prey populations are structured as metapopulations.

In this system, predators affect within-patch prey population dynamics in two ways: predators directly affect prey within local populations where predators and prey coincide (local effects, Fig. 1), and predators also change the flux of prey that leave or colonize the local population, thereby affecting recipient remote prey populations that do not contain predators (remote effects). As mentioned earlier, remote effects arise via two mechanisms: 1) consumptive effects, where predators reduce rates of prey flux among patches by directly consuming prey within local populations, 


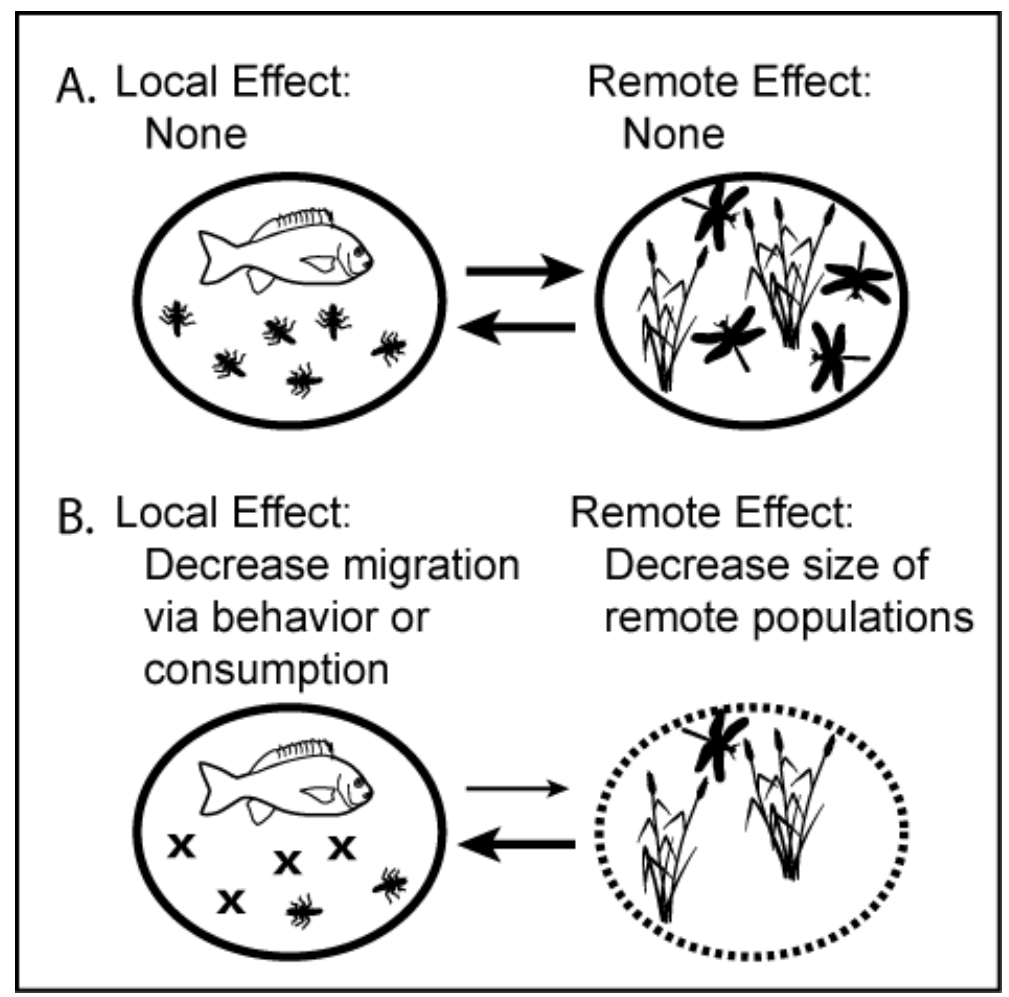

Fig. (3). Remote effects can also be generated when habitat shifts during prey ontogeny provide a refuge from predation. In this example, aquatic prey move to adjacent terrestrial habitats upon metamorphosis, where aquatic predators cannot follow. However, aquatic predators can influence the number of prey available for metamorphosis by consuming prey or by reducing rates of prey development, creating remote effects in the recipient terrestrial system. Although not shown, remote effects of predators that arise due to ontogenic niche shifts may also change the average phenotype of prey arriving in the recipient system. For example, larval anurans may undergo more rapid metamorphosis in predator-containing aquatic habitats, such that post-metamorphic individuals that move into terrestrial habitats are of smaller body size when predators are present in the aquatic habitat.

thereby reducing the number of individuals available to disperse; 2) non-consumptive effects, whereby predators increase or decrease rates of prey flux by influencing prey movement (i.e., changing the likelihood that an individual will disperse or the mean phenotype of dispersers). For example, the dynamics of fish populations (prey) in predator-free tributaries are a function of predators in connecting streams not only because consumption by predatory fish reduces dispersal of smaller fish (Fraser et al. 1995), but also because surviving prey are more likely to disperse from areas that contain predators (Fraser et al. 1999, Gilliam and Fraser 2001). Non-consumptive remote effects also arise when mobile prey choose to avoid otherwise suitable habitats that contain predators (e.g., Kats and Sih 1992, Resetarits 2001, Resetarits 2005, Resetarits et al. 2005, Resetarits and Binckley 2009). For example, beetles that choose to oviposit in predator-free pools generate the remote effect of "spatial contagion" in predator-free patches due to the presence of nearby predator-containing patches (Resetarits and Binckley 2009). For remote effects to occur, the matrix separating local prey populations need not be confined to the same ecosystem or life stage. As we discuss below, remote effects may operate within specific life-history stages and ecosystems, but may also be common when ontogenetic changes in prey habitat use with ontogeny (e.g., Benard and McCauley 2008, McCoy et al. 2009) create spatially and temporally structured prey populations (Fig. 3).

\section{WHEN ARE REMOTE EFFECTS LIKELY TO BE IMPORTANT?}

To examine how remote effects may alter prey dynamics, we consider how the dynamics of a hypothetical local prey population (within a larger prey metapopulation) might depend on the relative contribution of local and remote effects (Table 1). All else being equal, remote effects of predators on prey are more important if predators cause large changes in prey abundance via predation in the source patch (before prey have the opportunity to disperse), if they elicit large changes in prey movement rates, or if prey are not limited by bottom-up forces in local populations. The relative balance of several factors should affect prey dispersal rates. For example, dispersal rates will be relatively high if: benefits of staying in the source patch are low (e.g. the patch has low resources for prey), costs of staying are high (e.g., predators are voracious and prey are not well defended), costs of dispersing are low (e.g., prey have good dispersal ability and the matrix habitat is not risky), and benefits of dispersing are high (e.g., other patches are predator-free or lower risk). Interestingly, in some systems, when predation risk is very high, it can be so dangerous for prey to move through the habitat to disperse that predators suppress prey dispersal (Wooster and Sih 1995, McIntosh et al. 2002). Because the strength of predator-induced dispersal also depends upon the magnitude and effectiveness of prey defensive behavior, remote effects might also depend upon 
Table 1. Characteristics of Predator-Prey Systems and Proposed Mechanisms that may Determine the Influence of Remote Effects on Local Prey Population Dynamics

\begin{tabular}{|c|c|c|}
\hline Characteristic & Mechanism & Outcome \\
\hline $\begin{array}{l}\text { Prey behavioral or } \\
\text { morphological defenses }\end{array}$ & $\begin{array}{l}\text { Effective anti-predator defense reduces changes in prey abundance and eliminates } \\
\text { need to migrate }\end{array}$ & $\begin{array}{l}\text { Fewer populations influenced by } \\
\text { remote effects }\end{array}$ \\
\hline Predator lethality & Predators greatly reduce prey survival, reducing number of prey to migrate & $\begin{array}{l}\text { Fewer populations experience } \\
\text { remote effects }\end{array}$ \\
\hline Predator ferocity & Predators reduce prey activity, suppressing prey migration & $\begin{array}{l}\text { Fewer populations experience } \\
\text { remote effects }\end{array}$ \\
\hline Presence of spatial refuge & $\begin{array}{l}\text { Predators cannot enter the refuge, all effects of predators in the refuge are } \\
\text { indirectly mediated via prey }\end{array}$ & $\begin{array}{l}\text { Refuge populations experience } \\
\text { remote effects }\end{array}$ \\
\hline Predator abundance & $\begin{array}{c}\text { Most prey populations experience local effects when predators are common (i.e., } \\
\text { no transient refuge from predation) }\end{array}$ & $\begin{array}{l}\text { Fewer populations influenced by } \\
\text { remote effects }\end{array}$ \\
\hline Remote prey abundance & $\begin{array}{l}\text { Prey are restricted from entering remote, recipient population by conspecifics or } \\
\text { competitors }\end{array}$ & $\begin{array}{l}\text { Reduce remote effects in } \\
\text { recipient population }\end{array}$ \\
\hline Movement type & Directed movement may concentrate prey in remote patches & $\begin{array}{l}\text { Remote effects augmented in } \\
\text { remote patches }\end{array}$ \\
\hline
\end{tabular}

the prey's evolutionary history with predators (McIntosh and Townsend 1994, Sih et al. 2010). More subtly, remote effects of predators may be more important if predation risk causes a large shift in the mean (or variance) in the phenotype of dispersers (e.g., in their size, condition, or behavior; Fraser et al. 2001, Benard and McCauley 2008).

\section{REMOTE EFFECTS IN REFUGE-BASED PREY POPULATIONS}

Remote effects of predators may arise if predators are permanently absent from some local prey populations, i.e. when some local prey populations exist in permanent refuges. Many ecological systems have small-scale refuges capable of supporting local prey populations (e.g., Sih et al. 1985, Lima 1998) where predators can be excluded from refuges due to large size (i.e., they cannot fit within the refuge), or other morphological constraints (e.g., predators cannot cling to rocks in fast-moving waters; Hart and Finelli 1999), because predators cannot persist in the refuge (e.g. ephemeral bodies of water used for breeding by larval insects and amphibians rarely harbor fish predators), or because predators face increased risk there from predators of their own. Because predators can never consume or frighten prey in the refuge population, all effects of predators on local prey populations within a refuge are remote effects (Fig. 1).

Prey that experience ontogenic niche shifts (e.g., amphibian larvae or aquatic insects emerging from water to land) also provide a situation where predators may generate remote effects (Fig. 3), because these prey may escape most of their current predators when they change habitats. For example, predators during early life stages can reduce the number of prey (e.g., Vonesh 2005b, Vonesh and Bolker 2005) or average prey phenotypes (Peckarsky et al. 2001, Benard 2004, Benard and McCauley 2008) in subsequent habitats, as well as change transition rates between ontogenic niches, e.g. egg hatching rates (Vonesh 2005a). All of these changes have the ability to affect the quantity and quality of prey that arrive in the recipient population.

\section{Remote Effects within Transient Refuges}

In contrast, other refuges are transient: predators may be currently absent from a given site, but they can re-colonize at a later time. Because local populations in transient refuges are not always free of predators, the relative importance of local versus remote effects on prey populations will be a function of the frequency with which predators visit each patch of prey and prey migration rates (Table 1). As the proportion of prey patches experiencing predation at a given time increases, the relative strength of remote effects averaged across the metapopulation is necessarily reduced, because frequent predator visitation brings the majority of local prey populations under the control of local predation (i.e., predators directly affect the majority of prey patches most of the time). Conversely, if predators visit only a small proportion of local prey populations, predators may exert a larger remote effect across the prey metapopulation if prey disperse and thus transmit the signal of predation to the many remote populations more rapidly than predators visit them. Thus, remote effects are predicted to play a larger role in overall dynamics in systems where rates of prey flux are large relative to the movement rates of predators (Table 1), as might occur in systems where predator movement is costly, alternative prey exist, predators lack good 
information about prey distribution, predators have sedentary lifestyles (e.g. sit-and-wait predators), or predator space use is anchored by factors other than prey distribution (e.g. territoriality, distribution of mates). For example, a farranging, slow moving predator that is frightening or voracious but only visits a few prey patches each season may affect a majority of prey populations via remote effects. Changes in prey behavior that persist in time may also contribute to remote effects in transient refuges, e.g. if prey remain apprehensive for some period of time after the departure of a predator.

\section{Characteristics of Prey Populations}

Although predators generate remote effects, characteristics of recipient prey populations can determine whether remote effects influence prey dynamics. If local prey populations are saturated with conspecifics or superior competitors, i.e. they are soft sinks, remote effects will be diminished because arriving prey will be quickly lost due to competition and thus be unable to influence recipient patches. Conversely, remote effects should be more important if recipient populations are not saturated or immigrating prey are superior competitors that can displace residents or depress resources in recipient local prey populations. In dynamic systems where prey can direct movement and actively choose among habitats, the balance between predation risk in the donor population and the strength of competition in the recipient population may generate an ideal free distribution of prey (Morris 2003), i.e. habitat selection that is guided by remote effects.

Abiotic factors that influence prey populations by dictating the rate and direction of organism migration may also dictate the importance of remote effects. For example, in stream ecosystems characterized by rapid currents and organisms that drift downstream to escape predators, remote effects of predators may be greater than in still-water systems where escape responses of prey may not remove individuals from the local population. Landscape characteristics that affect prey movement (e.g. barriers, corridors) may alter which local prey populations receive remote effects. For example, in stream systems, prey drift primarily in one direction, such that downstream populations are more likely to experience remote effects from upstream predators or their cues (e.g., Wooster and Sih 1995, McIntosh et al. 2002).

\section{IMPLICATIONS OF REMOTE EFFECTS}

\section{Prey Populations}

By changing the density of prey that leave donor populations, predators could lead to remote effects on prey growth, morphology, development, and population dynamics within recipient local prey populations (e.g., Pangle et al. 2007). These remote effects may also occur where prey undergo ontogenic niche shifts (Benard and McCauley 2008, Schreiber and Rudolf 2008). For example, consumption of frog eggs by arboreal predators can reduce the flux of tadpoles into aquatic habitats (e.g., Vonesh 2005a) and consumption by aquatic predators can reduce the flux of emerging insects and amphibians to terrestrial habitats (Baxter et al. 2005, Finlay and Vredenburg 2007); the community-level consequences of these remote effects are discussed the following section.

Remote effects may affect metapopulation persistence by changing the size and composition of prey populations that comprise the metapopulation. Structured metapopulation models demonstrate that local population dynamics may alter rates of metapopulation extinction and determine the number of populations in the metapopulation at equilibrium (Gyllenberg et al. 1997). By increasing or decreasing rates of prey dispersal, predators may foster the persistence or extinction, respectively, of prey metapopulations via remote effects (Prakash and de Roos 2002, Reed and Levine 2005, Orrock et al. 2008). Aphid metapopulations may be an example of such remote effects, as the presence of predators causes the increased production of winged dispersal morphs (Dixon and Agarwala 1999). The presence of fish predators also increases the emigration rates of aquatic arthropod prey (McCauley and Rowe 2010). Remote effects may also be realized via predator-dependent habitat selection, which effectively changes the likelihood of immigration into predator-containing and predator-free patches. For many vertebrate and invertebrate taxa with aquatic life-history stages, colonization and oviposition are sensitive to whether predators are present (Kats and Sih 1992, Resetarits 2001, Blaustein et al. 2004, Binckley and Resetarits 2005). Thus, landscape-level patterns of prey distribution may be governed in large part by predator-sensitive habitat selection (Resetarits 2005, Resetarits et al. 2005), resulting in strong remote effects on prey distribution by predators to which prey are not directly exposed and yielding prey populations structured by spatial contagion of risk (Resetarits and Binckley 2009).

Remote effects can also have important consequences for conservation of prey populations by decoupling prey density and habitat quality. If predators cause prey to move from a high- to a low-resource site, then prey abundance can be negatively correlated with resource quality, leading to low abundance of prey in habitats that are effectively source populations and high abundance of prey in habitats that are effectively population sinks (Pulliam 1988). This scenario can confound habitat evaluations conducted for conservation purposes, because habitats where prey are most abundant are not necessarily the highest-quality habitats. This discrepancy in habitat quality and prey abundance would be expected to be greatest for prey with limited information about other habitats and limited ability to act on that information due to high costs of movement or low movement ability. For example, prey that drift downstream in response to a local predator may trade current predation risk for settlement in a habitat of unknown quality downstream. In systems where the mobile prey that trade food and safety are pursued by mobile predators, frequent movement among habitats and increased availability of information about habitats increases the likelihood that prey distribution in a particular habitat will reflect the joint consideration of the quality and risk in that habitat.

Remote effects may also alter rates of evolution within prey metapopulations via at least two mechanisms. First, remote effects may change the effective size of the metapopulation by changing the absolute number of individuals within local prey populations, the demographic composition 
of prey populations, and by contributing to heterogeneity in the size of local populations within the metapopulation (Barton and Whitlock 1997). Second, by changing the flux of particular prey genotypes (Urban and Skelly 2006), predators may potentially generate gene swamping (Lenormand 2002) in remote prey populations, such that anti-predator adaptations are maintained or fixed in populations where predators are not often present. This remote effect could yield prey populations adapted to predators they have not yet encountered, but could also create potentially deleterious prey phenotypes in the refuge (e.g. if prey are overly timid; Riechert 1993).

\section{Community-Level Dynamics}

The importance of spatial subsidies in food webs has received increasing attention in recent years (Polis et al. 1997). Applied to predator-prey systems, spatial subsidies often focus on unidirectional flows, such that prey moving from donor patches affect predators in recipient patches, but predators cannot affect the subsidy of prey. The concept of remote effects expands the domain of spatial subsidies by emphasizing how predators can alter subsidies of prey, and provides explicit mechanisms capable of generating this shift in prey subsidies. These remote prey subsidies are likely to have a variety of community-level effects in remote habitats by changing prey abundance and phenotype. For example, arboreal egg predators can alter subsidies of prey to aquatic and terrestrial habitats, remotely altering predator-prey interactions in both (e.g., Vonesh and Osenberg 2003, Vonesh $2005 \mathrm{~b}$, Vonesh and Bolker 2005). Subsidies of prey moving across local communities (and often habitat boundaries) may give rise to cross-system cascades (Baxter et al. 2005, Knight et al. 2005, Finlay and Vredenburg 2007) as well as apparent competition (McCoy et al. 2009); both of these dynamics arise from remote effects because they are initiated by predator-mediated changes in prey flux from the donor habitat. For example, consumption of aquatic invertebrates by exotic trout reduces food subsidies to web-building spiders and adult amphibians in adjacent terrestrial habitats because fewer insects emerge (Baxter et al. 2005, Finlay and Vredenburg 2007). Predator-mediated changes in the abundance of aquatic amphibians may yield remote effects on terrestrial habitats within the "predator shadow" caused when amphibians transform into terrestrial adults (McCoy et al. 2009). Knight and colleagues (2005) document a crosssystem cascade where the final recipient is far removed from the remote predator initiating the cascade. Fish predators reduce the number of dragonfly larvae available to emerge. Because fewer adult dragonflies are available to prey on pollinators of terrestrial plants, plants near fish-containing ponds experience increased rates of pollination (Knight et al. 2005), an interaction mediated by a consumptive remote effect.

Just as remote effects may be important for metapopulation dynamics, they are likely to be important components of metacommunity dynamics (Leibold et al. 2004). For example, one process affecting metacommunity dynamics is mass effects, whereby competitively inferior species are maintained in a local community due to continual immigration (Leibold et al. 2004). By changing rates of immigration, either through altering the number of active migrants (Sih and Wooster 1994, McIntosh et al. 2002), through habitat selection behavior (Resetarits 2005, Resetarits et al. 2005, Resetarits and Binckley 2009, Kraus and Vonesh 2010), or both, remote predators could readily alter the importance of mass effects for determining community composition (Resetarits et al. 2005, Orrock et al. 2008). The effects of predators on habitat selection by prey can have persistent effects on local community structure even in the presence of strong post-colonization processes (Vonesh et al. 2009). Recent work reveals the potential for remote effects to be important in this context, as habitat selection creates spatial contagion of predator effects into predator-free patches located near predator-containing patches (Resetarits and Binckley 2009). Moreover, predator-mediated habitat selection may interact with community assembly (Kraus and Vonesh 2010), suggesting that remote effects of predators may have context-specific implications for community structure.

Remote effects could also alter the similarity of local prey communities in space because prey migration can essentially homogenize recipient prey communities. This perspective emphasizes that predators and their remote effects are essential to understanding patterns of alpha diversity (Resetarits and Binckley 2009) as well as patterns of beta diversity (i.e., species turnover). Although recent evidence suggest that local predators may homogenize prey communities (Chase et al. 2009), the possibility of remote effects on turnover remains unexamined.

\section{QUANTIFYING REMOTE EFFECTS}

The potential exists for remote effects to confound ecological studies because remote effects may be cryptic and studies are rarely designed to detect them. Just as rates of prey migration may confound detection of local predator impacts (Cooper et al. 1990), investigators studying a prey species in a given focal site would not necessarily imagine that predators elsewhere could be having a major impact on their study population, and effects of remote predators could be incorrectly attributed to other mechanisms.

As a first approximation, quantifying the impact of remote effects on the dynamics of prey in a specific locality (e.g. habitat A) can be accomplished by removing predators from another locality (habitat B) over the appropriate temporal and spatial scale and observing whether the removal of a predator from B affects the dynamics within A. Building upon this approach, a more rigorous examination of remote effects would cross a predator manipulation treatment with a prey manipulation treatment, and would be explicitly designed to track prey that emigrate and measure their effects in locations where they settle. Within this experimental context, it would also be informative to use caged predators or predator cues to determine the degree to which remote predator effects were generated by consumptive or nonconsumptive effects on local prey and whether particular prey phenotypes are more involved in remote effects. Given the inherently spatial nature of remote effects, measuring the spatial extent of remote control by manipulating predators in source patches and quantifying remote effects on recipient prey populations at predator-free patches at varying distances 
from the manipulated predator source patch would also be a useful area of future study.

Importantly, experiments to quantify remote effects must be conducted at spatial scales large enough, and time scales long enough, to capture the relevant local and remote spatial dynamics of predators and prey. Although such a proposition that is daunting and rarely realized (Cronin and Reeve 2005), several recent studies can be used as models for future investigations (e.g., Vonesh and Osenberg 2003, Binckley and Resetarits 2005, Resetarits 2005, Resetarits et al. 2005, Vonesh et al. 2009, Kraus and Vonesh 2010).

\section{CONCLUSIONS}

Ecologists have produced a large body of evidence on the impacts of predators, documenting that predators cause changes in the behavior, morphology, development, and abundance of prey, as well as the indirect consequences of those changes. The concept of remote effects acknowledges that there are indirect spatial consequences that arise from the ecology of consumption as well as the ecology of nonconsumptive effects: prey behavior and mortality in one locality affect prey dynamics in areas where predators are not imminent sources of danger. Because the mechanisms that create the potential for remote effects are so widespread and well known, the concept of remote effects is not new (see, e.g., Englund 1997, Werner and Peacor 2003). Indeed, the existence of widespread mechanisms capable of creating remote effects suggests that the paucity of studies that examine and quantify remote effects may greatly limit our insight into the spatial dynamics of individuals, populations, and communities.

Although the relative importance of remote effects may be predictable based upon the characteristics of predators, prey, and the systems they inhabit (Table 1), remote effects can be cryptic as well as dynamic, and consequently could readily confound ecological studies. Given the importance of cross-boundary flows of organisms (e.g., Kremen et al. 2007, Marczak et al. 2007) an exciting challenge of both basic and applied relevance is to determine how often predators have remote effects, whether remote impacts frequently generate shifts in populations, communities, and food webs, and whether those impacts are generally predictable (Table 1).

\section{ACKNOWLEDGEMENTS}

This manuscript was improved by constructive comments and suggestions from P. Abrams, J. Chase, R. Fletcher, D. Finke, N. Gotelli, J. Kraus, T. Wootton, the laboratory group of Monica Turner at the Univ. of Wisconsin, and the Vonesh lab group at Virginia Commonwealth Univ. We also appreciate insightful comments from J. Laundré and B. Kotler. This work was conducted as part of the "Does Fear Matter?" Working Group supported by the National Center for Ecological Analysis and Synthesis (NCEAS), funded by NSF (Grant \#DEB-0072909), the Univ. California, and the UC Santa Barbara Campus. Symbols and graphics used to create conceptual figures were courtesy of the Integration and Application Network (ian.umces.edu/symbols/), Univ. Maryland Center for Environmental Science.

\section{REFERENCES}

Abrams, PA (2007) Defining and measuring the impact of dynamics traits on interspecific interactions. Ecology, 88, 2555-62.

Barton, NH \& Whitlock, MC (1997) The evolution of metapopulations. In Hanski, IA \& Gilpin, ME (Eds.) Metapopulation biology: ecology, genetics, and evolution. Academic Press, New York.

Baxter, CV, Fausch, KD \& Saunders, WC (2005) Tangled webs: reciprocal flows of invertebrate prey link streams and riparian zones. Freshwater Biology, 50, 201-20.

Benard, MF (2004) Predator-induced phenotypic plasticity in organisms with complex life histories. Annual Review of Ecology Evolution and Systematics, 35, 651-73.

Benard, MF \& McCauley, SJ (2008) Integrating across life-history stages: consequences of natal habitat effects on dispersal. American Naturalist, 171, 553-67.

Binckley, CA \& Resetarits, WJ (2005) Habitat selection determines abundance, richness and species composition of beetles in aquatic communities. Biology Letters, 1, 370-74.

Blaustein, L, Kiflawi, M, Eitam, A, Mangel, M \& Cohen, JE (2004) Oviposition habitat selection in response to risk of predation in temporary pools: mode of detection and consistency across experimental venue. Oecologia, 138, 300-5.

Brown, JS \& Kotler, BP (2004) Hazardous duty pay and the foraging cost of predation. Ecology Letters, 7, 999-1014.

Brown, JS, Laundre, JW \& Gurung, M (1999) The ecology of fear: Optimal foraging, game theory, and trophic interactions. Journal of Mammalogy, 80, 385-99.

Chase, JM, Biro, BG, Ryberg, WA \& Smith, KG (2009) Predators temper the relative importance of stochastic processes in assembly of prey communities. Ecology Letters, 12, 1210-8.

Cooper, SD, Walde, SJ \& Peckarsky, BL (1990) Prey exchange-rates and the impact of predators on prey populations in streams. Ecology, 71, 1503-14.

Creel, S \& Christianson, D (2008) Relationships between direct predation and risk effects. Trends in Ecology and Evolution, 23, 194-201.

Cronin, JT, Haynes, KJ \& Dillemuth, F (2004) Spider effects on planthopper mortality, dispersal, and spatial population dynamics. Ecology, 85, 2134-43.

Cronin, JT \& Reeve, JD (2005) Host-parasitoid spatial ecology: a plea for a landscape-level synthesis. Proceedings of the Royal Society BBiological Sciences, 272, 2225-35.

Dixon, AFG \& Agarwala, BK (1999) Ladybird-induced life-history changes in aphids. Proceedings of the Royal Society Series B-Biological Sciences, 266, 1549-53.

Englund, G (1997) Importance of spatial scale and prey movements in predator caging experiments. Ecology, 78, 2316-25.

Finlay, JC \& Vredenburg, VT (2007) Introduced trout sever trophic connections in watersheds: Consequences for a declining amphibian. Ecology, 88, 2187-98.

Fraser, DF, Gilliam, JF, Daley, MJ, Le, AN \& Skalski, GT (2001) Explaining leptokurtic distributions: intrapopulation variation in boldness and exploration. American Naturalist, 158, 124-35.

Fraser, DF, Gilliam, JF, MacGowan, MP, Arcaro, CM \& Guillozet, PH (1999) Habitat quality in a hostile river corridor. Ecology, 80, 597 607.

Fraser, DF, Gilliam, JF \& Yiphoi, T (1995) Predation as an agent of population fragmentation in a tropical watershed. Ecology, 76, 1461-72.

Gilliam, JF \& Fraser, DF (2001) Movement in corridors: Enhancement by predation threat, disturbance, and habitat structure. Ecology, 82, 258-73.

Gyllenberg, M, Hanski, I \& Hastings, A (1997) Structured metapopulation models. In: Hanski, IA \& Gilpin, ME (Eds) Metapopulation biology: ecology, genetics, and evolution. New York, Academic Press.

Hanski, IA \& Gilpin, ME (1997) Metapopulation biology: ecology, genetics, and evolution, Academic Press, San Diego.

Hart, DD \& Finelli, CM (1999) Physical-biological coupling in streams: The pervasive effects of flow on benthic organisms. Annual Review of Ecology and Systematics, 30, 363-95.

Kats, LB \& Sih, A (1992) Oviposition site selection and avoidance of fish by streamside salamanders (Ambystoma barbouri). Copeia, 468-73.

Knight, TM, McCoy, MW, Chase, JM, McCoy, KA \& Holt, RD (2005) Trophic cascades across ecosystems. Nature, 437, 880-3. 
Kraus, JM \& Vonesh, JR (2010) Feedbacks between community assembly and habitat selection shape variation in local colonization. Journal of Animal Ecology, 79, 795-802.

Kremen, C, Williams, NM, Aizen, MA, Gemmill-Herren, B, LeBuhn, G, Minckley, R, Packer, L, Potts, SG, Roulston, T, Steffan-Dewenter, I, Vazquez, DP, Winfree, R, Adams, L, Crone, EE, Greenleaf, SS, Keitt, TH, Klein, AM, Regetz, J \& Ricketts, TH (2007) Pollination and other ecosystem services produced by mobile organisms: a conceptual framework for the effects of land-use change. Ecology Letters, 10, 299-314.

Leibold, MA, Holyoak, M, Mouquet, N, Amarasekare, P, Chase, JM, Hoopes, MF, Holt, RD, Shurin, JB, Law, R, Tilman, D, Loreau, M \& Gonzalez, A (2004) The metacommunity concept: a framework for multi-scale community ecology. Ecology Letters, 7, 601-13.

Lenormand, T (2002) Gene flow and the limits to natural selection. Trends in Ecology and Evolution, 17, 183-9.

Lima, SL (1998) Nonlethal effects in the ecology of predator-prey interactions. Bioscience, 48, 25-34.

Lima, SL \& Dill, LM (1990) Behavioral decisions made under the risk of predation - a review and prospectus. Canadian Journal of Zoology, $68,619-40$.

Marczak, LB, Thompson, RM \& Richardson, JS (2007) Meta-analysis: Trophic level, habitat, and productivity shape the food web effects of resource subsidies. Ecology, 88, 140-8.

McCauley, SJ \& Rowe, L (2010) Notonecta exhibit threat-sensitive, predator-induced dispersal. Biology Letters, 6, 449-52.

McCoy, MW, Barfield, M \& Holt, RD (2009) Predator shadows: complex life histories as generators of spatially patterned indirect interactions across ecosystems. Oikos, 118, 87-100.

McIntosh, AR, Peckarsky, BL \& Taylor, BW (2002) The influence of predatory fish on mayfly drift: extrapolating from experiments to nature. Freshwater Biology, 47, 1497-513.

McIntosh, AR \& Townsend, CR (1994) Interpopulation variation in mayfly anti-predator tactics: differential effects of contrasting predatory fish. Ecology, 75, 2078-90.

McPeek, MA (1989) Differential dispersal tendencies among Enallagma damselflies (Odonata) inhabiting different habitats. Oikos, 56, 18795.

Morris, DW (2003) Toward an ecological synthesis: a case for habitat selection. Oecologia, 136, 1-13.

Orrock, JL, Grabowski, JH, Peacor, SD, Peckarsky, BL, Preisser, EL, Sih, A $\&$ Werner, EE (2008) Consumptive and non-consumptive effects of predators on metacommunities of competing prey. Ecology, 89, 2426-35.

Pangle, KL, Peacor, SD \& Johannsson, OE (2007) Large nonlethal effects of an invasive invertebrate predator on zooplankton population growth rate. Ecology, 88, 402-12.

Peacor, SD \& Werner, EE (2001) The contribution of trait-mediated indirect effects to the net effects of a predator. Proceedings of the National Academy of Sciences of the United States of America, 98, 3904-8.

Peckarsky, BL, Bolnick, DI, Dill, LM, Grabowski, JH, Luttbeg, B, Orrock, JL, Peacor, SD, Preisser, E, Schmitz, O \& Trussell, GC (2008) Revisiting the classics: Considering nonconsumptive effects in textbook examples of predator-prey interactions. Ecology, 89, 2416-25.

Peckarsky, BL, Taylor, BW, McIntosh, AR, McPeek, MA \& Lytle, DA (2001) Variation in mayfly size at metamorphosis as a developmental response to risk of predation. Ecology, 82, 740-57.

Polis, GA, Anderson, WB \& Holt, RD (1997) Toward an integration of landscape and food web ecology: The dynamics of spatially subsidized food webs. Annual Review of Ecology and Systematics, $28,289-316$

Prakash, S \& de Roos, AM (2002) Habitat destruction in a simple predatorprey patch model: How predators enhance prey persistence and abundance. Theoretical Population Biology, 62, 231-49.
Preisser, EL, Bolnick, DI \& Benard, MF (2005) Scared to death? The effects of intimidation and consumption in predator-prey interactions. Ecology, 86, 501-9.

Preisser, EL, Orrock, JL \& Schmitz, OJ (2007) Predator hunting mode and habitat domain alter nonconsumptive effects in predator-prey interactions. Ecology, 88, 2744-51.

Pulliam, HR (1988) Sources, sinks, and population regulation. American Naturalist, 132, 652-61.

Reed, JM \& Levine, SH (2005) A model for behavioral regulation of metapopulation dynamics. Ecological Modelling, 183, 411-23.

Resetarits, WJ (2001) Colonization under threat of predation avoidance of fish by an aquatic beetle, Tropisternus lateralis (Coleoptera: Hydrophilidae). Oecologia, 129, 155-60.

Resetarits, WJ (2005) Habitat selection behaviour links local and regional scales in aquatic systems. Ecology Letters, 8, 480-6.

Resetarits, WJ \& Binckley, CA (2009) Spatial contagion of predation risk affects colonization dynamics in experimental aquatic landscapes. Ecology, 90, 869-76.

Resetarits, WJ, Jr., Binckley, CA \& Chalcraft, DR (2005) Habitat selection, species interactions, and processes of community assembly in complex landscapes: a metacommunity perspective. In: Holyoak, M, Leibold, MA \& Holt, RD (Eds) Metacommunities: spatial dynamics and ecological communities. University of Chicago Press, Chicago.

Riechert, SE (1993) The evolution of behavioral phenotypes: Lessons learned from divergent spider populations. Advances in the Study of Behavior, 22, 103-34.

Schmitz, OJ, Krivan, V \& Ovadia, O (2004) Trophic cascades: the primacy of trait-mediated indirect interactions. Ecology Letters, 7, 153-63.

Schreiber, S \& Rudolf, VHW (2008) Crossing habitat boundaries: coupling dynamics of ecosystems through complex life cycles. Ecology Letters, 11, 576-87.

Sih, A, Bolnick, DI, Luttbeg, B, Orrock, JL, Peacor, SD, Pintor, L, Preisser, E, Rehage, J \& Vonesh, JR (2010) Predator-prey naivete, antipredator behavior, and the ecology of predator invasions. Oikos, 119, 610-21.

Sih, A, Crowley, P, McPeek, M, Petranka, J \& Strohmeier, K (1985) Predation, competition, and prey communities - a review of field experiments. Annual Review of Ecology and Systematics, 16, 269311.

Sih, A \& Wooster, DE (1994) Prey behavior, prey dispersal, and predator impacts on stream prey. Ecology, 75, 1199-207.

Urban, MC \& Skelly, DK (2006) Evolving metacommunities: Toward an evolutionary perspective on metacommunities. Ecology, 87, 161626.

Vonesh, JR (2005a) Egg predation and predator-induced hatching plasticity in the African tree frog, Hyperolius spinigularis. Oikos, 110, 24152.

Vonesh, JR (2005b) Sequential predator effects across three life stages of the African tree frog, Hyperolius spinigularis. Oecologia, 143, 28090 .

Vonesh, JR \& Bolker, BM (2005) Compensatory larval responses shift trade-offs associated with predator-induced hatching plasticity. Ecology, 86, 1580-91.

Vonesh, JR, Krauss, JM, Rosenberg, JS \& Chase, JM (2009) Predator effects on aquatic community assembly: disentangling the roles of habitat selection and post-colonization processes. Oikos, 118, 121929.

Vonesh, JR \& Osenberg, CW (2003) Multi-predator effects across lifehistory stages: non-additivity of egg- and larval-stage predation in an African treefrog. Ecology Letters, 6, 503-8.

Werner, EE \& Peacor, SD (2003) A review of trait-mediated indirect interactions in ecological communities. Ecology, 84, 1083-100.

Wooster, D \& Sih, A. (1995) A review of the drift and activity responses of stream prey to predator presence. Oikos, 73, 3-8. 